\title{
Intraoral HIV-associated Burkitt's lymphoma: a rare case report with special emphasis on differential diagnosis
}

\author{
Mamata Kamat ${ }^{1}$, Uma Datar ${ }^{1}$, Sampada Kanitkar ${ }^{2}$, Sanjay Byakodi ${ }^{3}$ \\ Departments of ${ }^{1}$ Oral Pathology \& Microbiology and ${ }^{3}$ Oral \& Maxillofacial Surgery, Bharati Vidyapeeth (Deemed to be University) \\ Dental College and Hospital, ${ }^{2}$ Private Clinic, Sangli, India
}

\begin{abstract}
J Korean Assoc Oral Maxillofac Surg 2019;45:225-229)
Individuals with human immunodeficiency virus (HIV) infection present with unique intraoral manifestations of various neoplasms. Intraoral HIVassociated Burkitt's lymphoma is a rare presentation, especially in patients of Indian origin and may present as an initial sign of HIV. The objective of this paper is to report a rare case of Burkitt's lymphoma in an HIV-positive Indian patient along with a special emphasis on differential diagnosis. A 30-year-old Indian female presented with a solitary, well-defined, exophytic mass extending anteroposteriorly and buccolingually from the 35th to 38th regions with no evidence of intraosseous extension. An incisional biopsy was performed, and histopathology showed sheets of neoplastic lymphoid cells with numerous tingible body macrophages with clear cytoplasm, presenting a starry sky appearance, suggesting a diagnosis of BL. The tumor cells were positive for CD10, CD20, c-myc, and Epstein-Barr virus, with a nearly 100\% Ki-67 proliferative index. The patient tested positive for HIV. This report indicates the importance of immunohistochemical analysis to differentiate Burkitt's lymphoma from other similar lesions like diffuse large B-cell lymphoma. Thorough knowledge of the clinical presentation, etiopathogenesis, histopathology, and immunoprofile of intraoral HIV-associated Burkitt's lymphoma is essential among clinicians and pathologists.
\end{abstract}

Key words: Aquired immunodeficiency syndrome, Burkitt lymphoma, Gingiva, HIV, Oral cavity

[paper submitted 2017. 12. 26 / revised 2018. 3. 16 / accepted 2018. 3. 22]

\section{Introduction}

Non-Hodgkin's lymphoma (NHL) is one of the most common acquired immunodeficiency syndrome (AIDS)-defining neoplasms, accounting for one-third of AIDS-related malignancies ${ }^{1,2}$. Burkitt's lymphoma (BL) is an uncommon highly aggressive B-cell NHL, first described by Dr. Dennis Burkitt in $1958^{3,4}$. BL has the highest proliferation rate of any human neoplasm, with a possible doubling time of 24 hours $^{3}$. Three forms of BL have been described by World Health Organization (WHO): 1) Endemic, 2) sporadic, and 3) immunode-

\footnotetext{
Mamata Kamat

Department of Oral Pathology \& Microbiology, Bharati Vidyapeeth (Deemed to be University) Dental College and Hospital, Sangli 416416, India

TEL: +91-8412914777 FAX: +91-233-2211324

E-mail:kmamata@yahoo.com

ORCID: https://orcid.org/0000-0003-0167-531X

(c) This is an open-access article distributed under the terms of the Creative Commons Attribution Non-Commercial License (http://creativecommons.org/ licenses/by-nc/4.0/), which permits unrestricted non-commercial use, distribution, and reproduction in any medium, provided the original work is properly cited. Copyright (C) 2019 The Korean Association of Oral and Maxillofacial Surgeons. All rights reserved.
}

ficiency-associated ${ }^{4}$. BL exhibits an elevated incidence in immunocompromised patients, especially those with human immunodeficiency virus (HIV) infection, accounting for $2.4 \%$ to $20 \%$ of HIV-associated $\mathrm{NHLs}^{2,3}$. Extra nodal sites particularly in the abdomen and lymph node are the most common sites for HIV-associated BL, and intraoral lesions are very uncommon ${ }^{5,6}$. This subtype is considered one of the primary/ initial conditions indicating an underlying HIV infection ${ }^{6}$. Therefore, we report a case of HIV-associated BL presenting as an intraoral mass in a female Indian patient.

\section{Case Report}

A 30-year-old female reported to our institution with a chief complaint of an asymptomatic, gradually enlarging growth in the lower left back region of the jaw for 4 months. The patient did not reveal any significant medical history or drug allergies. Extraoral examination revealed facial asymmetry caused by a soft, painless swelling of the left cheek. An enlarged left submandibular lymph node was noted. Intraoral examination showed a solitary, well-defined, sessile, exo- 
phytic mass covered by slough, extending anteroposteriorly and buccolingually from the 35 th to 38 th region.(Fig. 1) The lesion was non-tender, soft in consistency, and measured approximately $3 \mathrm{~cm} \times 4 \mathrm{~cm}$ in diameter. Panoramic radiograph showed superficial bone loss in the area of the lesion, with no evidence of intraosseous extension. Considering these features, a provisional diagnosis of malignant tumor was suspected. Gingival enlargement, periodontal disease, fungal infection, granulomatous diseases like Wegener's granulomatosis, epithelial malignancies such as squamous cell carcinoma, connective tissue tumors like fibromatosis and fibrosarcoma, and lymphoproliferative disorders like lymphoma and leukemia were also considered in the differential diagnosis. Since these lesions are clinically indistinguishable, a histopathologic examination in the form of an incisional biopsy was performed, and the excised tissue was subjected

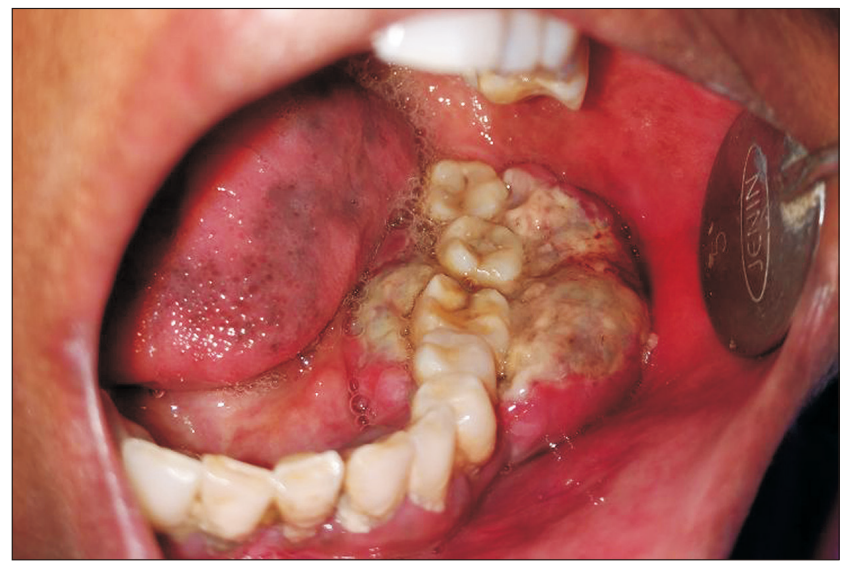

Fig. 1. Intraoral clinical image showing a sessile exophytic mass covered by slough, extending anteroposteriorly and buccolingually from the 35th to 38th region.

Mamata Kamat et al: Intraoral HIV-associated Burkitt's lymphoma: a rare case report with special emphasis on differential diagnosis. J Korean Assoc Oral Maxillofac Surg 2019 to histopathologic evaluation to obtain a confirmatory diagnosis.

Microscopic examination revealed diffuse proliferation of uniformly sized neoplastic lymphoid cells. The cells showed hyperchromatic round nuclei with multiple nucleoli and basophilic cytoplasm. Numerous tingible body macrophages with clear cytoplasm were seen interspersed among the tumor cells, producing a starry sky appearance.(Fig. 2. A) The cells also demonstrated pleomorphism and increased abnormal mitotic figures.(Fig. 2. B) Immunohistochemical analysis showed that the tumor cells were positive for c-myc, CD10, CD20, and Epstein-Barr virus (EBV) (Fig. 3. A-C, 3. E) and negative for $\mathrm{CD} 3, \mathrm{Bcl} 2, \mathrm{Bcl} 6$, and MUM1. The Ki67 proliferative index was nearly 100\%.(Fig. 3. D) Based on the histologic and immunohistochemical findings, the diagnosis was BL. Since this particular intraoral location of $\mathrm{BL}$ is uncommon in non-endemic regions, it was suspected that the patient might be immunocompromised. Therefore, the patient was asked to undergo serological testing for HIV, which turned out to be positive, resulting in a final diagnosis of HIV-associated BL. Unfortunately, further investigations could not be performed as the patient was lost to follow-up.

\section{Discussion}

Patients with HIV infection are at high risk of developing malignancies. NHL constitutes the second most common variety of these neoplasms and is considered an AIDS- defining entity $^{1}$. The most common types of NHLs seen in HIV/AIDS patients include diffuse large B-cell lymphoma (DLBCL) and BL, accounting for $7 \%$ to $20 \%$ of cases $^{7-9}$. Abdominal, nodal, and bone marrow involvement are frequent for HIV-associated BL, and Central Nervous System (CNS) involvement is seen in $13 \%$ to $17 \%$ of cases ${ }^{4,6}$. Intraoral locations are a
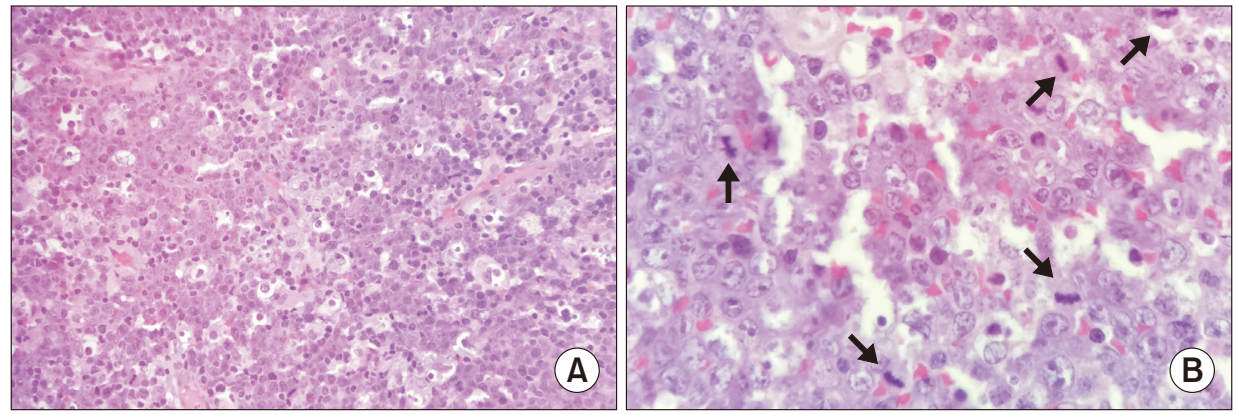

Fig. 2. Photomicrograph showing diffuse proliferation of uniformly sized neoplastic lymphoid cells with numerous tingible body macrophages, presenting a starry sky appearance (A: H\&E staining, $\times 10)$ and numerous mitotic figures, marked with arrows (B: H\&E staining, $\times 40)$.

Mamata Kamat et al: Intraoral HIV-associated Burkitt’s lymphoma: a rare case report with special emphasis on differential diagnosis. J Korean Assoc Oral Maxillofac Surg 2019 


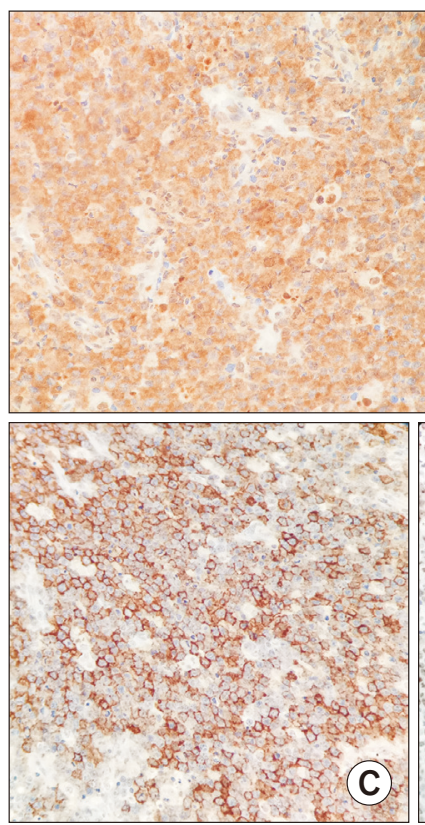

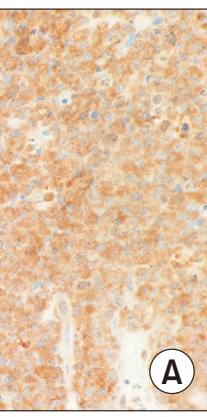
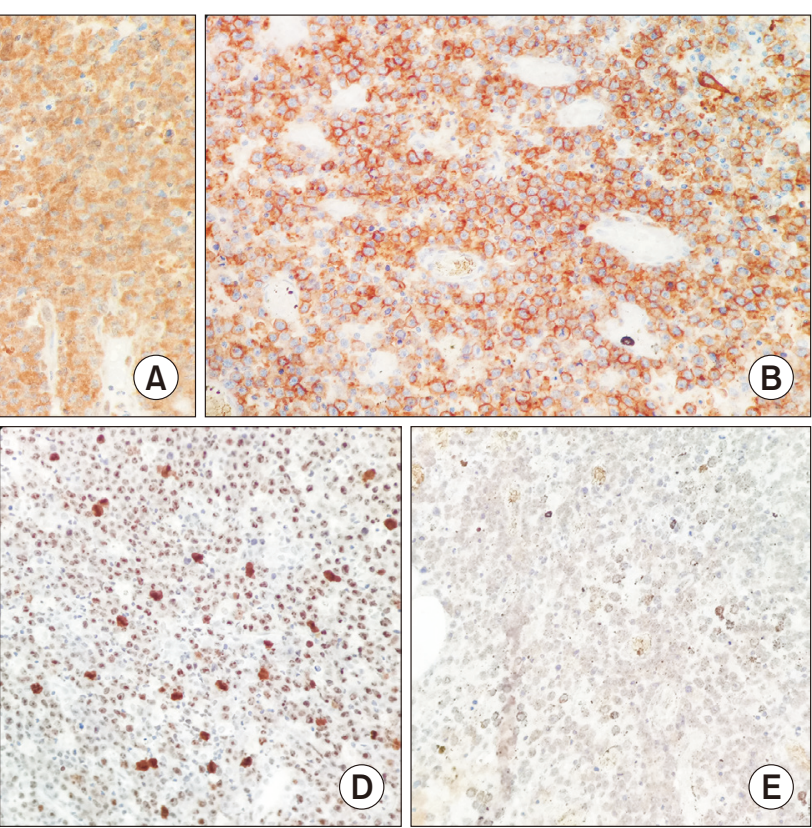

Fig. 3. Immunohistochemical staining showed that the neoplastic lymphoid cells were positive for $c-m y c(A: \times 10)$, CD10 (B: $\times 10)$, CD20 (C: ×10), Ki-67 (D: $\times 40)$, and Epstein-Barr virus $(\mathrm{E}: \times 10)$.

Mamata Kamat et al: Intraoral HIV-associated Burkitt's lymphoma: a rare case report with special emphasis on differential diagnosis. $J$ Korean Assoc Oral Maxillofac Surg 2019

Table 1. Summary of cases of intraoral HIV-associated Burkitt's lymphoma reported in the literature

\begin{tabular}{|c|c|c|c|c|}
\hline Study & No. of cases & Age $(y r) / s e x$ & Intraoral site & Immunohistochemical and molecular findings \\
\hline Langford et al. $^{13}(1991)$ & 1 & $42 / \mathrm{M}$ & Gingiva & $\begin{array}{l}\text { Positive for CD45RA, Ki-B3, L26, and CD45 } \\
\text { Negative for CD45RO, CD43, CD21, CD68, and CD30 }\end{array}$ \\
\hline Karlis et al. ${ }^{11}$ (1998) & 1 & $51 / \mathrm{M}$ & Gingiva & NA \\
\hline Jordan et al. $^{12}$ (1998) & 2 & $\begin{array}{l}59 / \mathrm{M} \\
46 / \mathrm{M}\end{array}$ & $\begin{array}{l}\text { Gingiva } \\
\text { Gingiva }\end{array}$ & NA \\
\hline Nittayananta et al. ${ }^{15}(1998)$ & 2 & $26 / M$ & Gingiva & $\begin{array}{l}\text { Positive for CD } 20 \text { and CD } 45 \\
\text { Negative for CD } 45 \text { RO and EBV }\end{array}$ \\
\hline Chen et al. ${ }^{10}(2005)$ & 1 & 28/M & Gingiva & $\begin{array}{l}\text { Positive for CD20, kappa, and c-myc } \\
\text { Negative for CD } 45 \mathrm{RO} \text {, lambda, CD30, Bcl2, Bcl6, and EBV } \\
\text { High labelling indices with Ki-67 and p53 }\end{array}$ \\
\hline Venkatesh et al. ${ }^{16}(2008)$ & 1 & $39 / \mathrm{M}$ & $\begin{array}{l}\text { Gingiva and } \\
\text { hard palate }\end{array}$ & NA \\
\hline Butt et al. ${ }^{18}(2008)$ & 1 & NA & Palate & NA \\
\hline Corti et al. ${ }^{14}(2011)$ & 3 & $\begin{array}{l}44 / \mathrm{M} \\
24 / \mathrm{F} \\
38 / \mathrm{M}\end{array}$ & $\begin{array}{l}\text { Gingiva, palate } \\
\text { Gingiva } \\
\text { Gingiva }\end{array}$ & $\begin{array}{l}\mathrm{EBV}+\mathrm{ve} \\
\text { EBV+ve } \\
\text { Not tested }\end{array}$ \\
\hline Goto et al. ${ }^{5}(2012)$ & 1 & $45 / \mathrm{F}$ & Gingiva & $\begin{array}{l}\text { Positive for CD10, CD79a, CD20, and Bc16 } \\
\text { Negative for CD3, CD5, cyclinD1, and Bc12 } \\
\text { Ki-67 index } 98 \%\end{array}$ \\
\hline Ajila et al. ${ }^{3}(2012)$ & 1 & $42 / \mathrm{M}$ & Gingiva & Not tested \\
\hline Komatsu et al. ${ }^{17}(2013)$ & 1 & $37 / \mathrm{M}$ & Floor of mouth & $\begin{array}{l}\text { Positive for CD19, CD20, and CD10 } \\
\text { Negative for CD3, CD4, and CD8 } \\
\text { c-myc rearrangement +ve by FISH }\end{array}$ \\
\hline Pinisetti et al. ${ }^{8}$ (2013) & 1 & $38 / \mathrm{F}$ & Gingiva & $\begin{array}{l}\text { Positive for CD20 } \\
\text { Negative for CD3 }\end{array}$ \\
\hline Sivolella et al. ${ }^{7}$ (2015) & 1 & $52 / \mathrm{M}$ & Mandibular jaw & $\begin{array}{l}\text { Positive for CD19, CD20, CD79a, CD10, and Bc16 } \\
\text { Negative for CD5, CD23, Bc12, and EBV } \\
\text { MIB-1 index } 100 \%\end{array}$ \\
\hline Mosalleum et al. ${ }^{6}$ (2015) & 1 & $25 / \mathrm{F}$ & Gingiva & $\begin{array}{l}\text { Positive for CD } 45, \text { CD20, CD10, and Bc16 } \\
\text { Ki- } 67 \text { index } 100 \% \\
\text { c-myc rearrangement +ve by FISH }\end{array}$ \\
\hline
\end{tabular}

(HIV: human immunodeficiency virus, M: male, F: female, NA: not analysed, EBV: Epstein-Barr virus, FISH: fluorescent in situ hybridization) Mamata Kamat et al: Intraoral HIV-associated Burkitt's lymphoma: a rare case report with special emphasis on differential diagnosis. J Korean Assoc Oral Maxillofac Surg 2019

relatively rare occurence ${ }^{10}$. A summary of literature reporting intraoral HIV-associated BL is depicted in Table 1.

Literature strongly suggests EBV infection and dysregula- tion of the c-myc (c-myelocytomatosis) oncogene as possible causes of $\mathrm{BL}^{7}$. Approximately $98 \%$ of endemic BL, $20 \%$ of sporadic BL, and $30 \%$ to $40 \%$ of immunodeficient BL ex- 
hibit an association with $\mathrm{EBV}^{2}$. EBV promotes B-cell hyperplasia, an essential step in lymphomagenesis. This increases the risk of chromosomal rearrangement associated with cmyc oncogene expression. The c-myc immunoglobulin (Ig) translocation is thought to arise as a result of errors in activation-induced cytidine deaminase-mediated Ig class switch recombination in germinal centers, leading to proliferation of neoplastic cells ${ }^{3,6-8}$. In addition, when HIV infection is associated with $\mathrm{BL}$, it causes uncontrolled polyclonal activation of B cells ${ }^{8}$.

Approximately $4 \%$ of NHLs associated with HIV occur in the oral cavity ${ }^{5}$. The data available regarding intraoral HIVassociated BL indicate the gingiva as the most frequently affected site and primary occurrence in males ${ }^{3,5-8,10-16}$. Lesions on the palate, floor of the mouth, and lower jaw have also been reported ${ }^{17,18}$. The most frequently affected ages were from the 3 rd to 5 th decades. A lesion usually presents as a rapidly growing ulcerative mass with a necrotic surface ${ }^{2,5,8,10}$. Intraoral and extraoral swelling along with tooth loosening and mobility are seen with jaw lesions ${ }^{3,7}$. Radiographic findings include ill-defined radiolucency with loss of trabecular pattern of the mandible or maxilla ${ }^{3}$. The present case involved an exophytic growth with surface ulceration in the mandibular gingiva in a 30-year-old female patient. Clinically, BL may mimic a variety of orofacial pathologies; hence, clinical differential diagnosis should include periodontal disease, deep fungal infection, granulomatous diseases, and malignant neoplasms ${ }^{15}$.

Microscopically, HIV-associated BL exhibits features of classic BL. These include diffuse monotonous proliferation of sheets of small to intermediate-sized malignant cells that exhibit moderately abundant basophilic cytoplasm with round, regular nuclei containing multiple nucleoli ${ }^{1,2}$ and abundant mitotic figures. Numerous scattered tangible body macrophages with clear cytoplasm (as a result of phagocytosis of apoptotic cells) form a starry-sky appearance ${ }^{1,5}$. Previously, the WHO had suggested three histological subtypes of HIVassociated BL: classic BL, BL with plasmacytoid differentiation, and atypical BL. However, these subtypes are no longer favored, and the variants have been described as a separate entity of B-cell lymphoma, unclassifiable with features intermediate between DLBCL and $\mathrm{BL}^{1,4}$.

Immunohistochemically, the tumor cells of BL show positivity for Pan B-cell antigens that include CD19, CD20, CD22, and CD79a; may co-express CD10, BCl-6, CD43, and p53; and show immunonegativity for MUM-1,CD5, CD23, BCL-2, CD138, and TdT (terminal deoxynucleotidyl trans- ferase $)^{2,7,8,19}$. This immunoprofile suggests a follicle center origin of BL. The tumor cells have a high proliferation rate, as shown with the nearly $100 \%$ nuclear reactivity of $\mathrm{Ki}-67^{20}$. In addition, chromosomal rearrangement of MYC is most common in the form of translocation of $\mathrm{t}(8 ; 14)$ detected by fluorescent in situ hybridization (FISH) ${ }^{1}$. The present case also showed immunoreactivity for CD10, CD20, c-myc, and EBV and immunonegativity for CD3, BCL2, BCL6, and MUM-1.

Features like the starry sky pattern, BL-like immunophenotype, and high proliferation fraction in some DLBCLs necessitates that BL be distinguished from DLBCL, as the two entities require different treatment modalities ${ }^{19}$. DLBCL is traditionally treated by CHOP (cyclophosphamide, doxorubicin, vincristine, and prednisone) therapy with the anti-B cell antibody rituximab, whereas adult $\mathrm{BL}$ frequently requires a high intensity chemotherapy regimen including CNS prophylaxis to improve overall survival ${ }^{19,20}$. The WHO recommends positivity for CD10, BCL6, and Ki-67 >90\%; negativity for BCL2 with the presence of a MYC breakpoint; and absence of BCL2 and/or BCL6 breakpoints for diagnosis of BL ${ }^{20}$. Therefore, researchers have reached a consensus regarding the practical approach for this differentiation and have suggested that positivity for CD10, BCL6, and Ki-67 >90\%; negativity for BCL2; presence of an MYC breakpoint; and absence of BCL2 and/or BCL6 breakpoints favor diagnosis of $\mathrm{BL}^{19,20}$. The differences between BL and DLBCL are depicted in Table 2. Our case showed positivity for CD10 (germinal center-associated marker ${ }^{17}$ ), CD20 (mature B cell with monotypic surface antigens ${ }^{6}$ ), c-myc, and EBV and negativity for CD3 (T-cell associated marker ${ }^{17}$ ), Bcl6, Bcl2 (marker for activated B- cell), and MUM1 (plasma cell marker ${ }^{14}$ ). Based on these findings, we confirmed the diagnosis of BL. Therefore, the final diagnosis of BL should be established with the help of immunohistochemistry and molecular investigations.

The primary mode of treatment for BL is intensive multi-

Table 2. Differences between Burkitt's lymphoma (BL) and diffuse large B-cell lymphoma (DLBCL) ${ }^{19}$

\begin{tabular}{lll}
\hline & \multicolumn{1}{c}{ BL } & \multicolumn{1}{c}{ DLBCL } \\
\hline Bcl2 & Negative & Positive \\
Ki-67 & $>95 \%$ & $<90 \%$ \\
c-myc & $\begin{array}{c}\text { Immunoglobulin-MYC } \\
\text { rearrangement } \\
\end{array}$ & Negative rearrangement \\
(simple karyotype) & \\
& & Bcl6-rearrangement \\
& & Bcl2-rearrangement \\
\hline
\end{tabular}

Mamata Kamat et al: Intraoral HIV-associated Burkitt's lymphoma: a rare case report with special emphasis on differential diagnosis. J Korean Assoc Oral Maxillofac Surg 2019 
agent chemotherapy. In HIV patients, modified protocols are used to reduce toxicity ${ }^{6}$. However, HIV-associated BL is less sensitive to chemotherapy compared to endemic forms and shows poor prognosis with a tendency to relapse ${ }^{5,8}$. In cases of extra nodal HIV-associated BL, thorough investigations should be performed to detect other sites of involvement, and patients should be treated accordingly.

In conclusion, the present case and analysis of previously reported cases suggest that intraoral $\mathrm{BL}$ can be the initial manifestation of HIV infection in patients. Therefore, such an oral presentation should raise the suspicion of an underlying immunocompromised state. BL should be differentiated from DLBCL, as they require different treatments. As a result, detailed knowledge on the etiopathogenesis, clinical presentation, and histopathology along with immunological and molecular profiles is critical to obtain a final diagnosis.

\section{ORCID}

\author{
Mamata Kamat, https://orcid.org/0000-0003-0167-531X \\ Uma Datar, https://orcid.org/0000-0002-0930-8875 \\ Sampada Kanitkar, https://orcid.org/0000-0001-9269-4596 \\ Sanjay Byakodi, https://orcid.org/0000-0002-1938-2761
}

\section{Authors' Contributions}

M.K. participated in data collection and wrote the manuscript. M.K., U.D., S.K., and S.B. participated in the design and performed the draft. U.D. participated in the coordination and helped to draft the manuscript. All authors read and approved the final manuscript.

\section{Consent for Publishing Photographs}

Written informed consent was obtained from the patients for publication of this article and accompanying images.

\section{Conflict of Interest}

No potential conflict of interest relevant to this article was reported.

\section{References}

1. Cesarman E. Pathology of lymphoma in HIV. Curr Opin Oncol 2013;25:487-94.

2. Corti M. Burkitt's lymphoma associated with HIV infection. Clin Microbiol 2016;5:232.
3. Ajila V, Gopakumar R, Hegde S, Babu SG. Intraoral Burkitt's lymphoma in an HIV positive patient. Indian J Sex Transm Dis AIDS 2012;33:118-20.

4. Swerdlow SH, Campo E, Harris NL, Jaffe ES, Pileri SA, Stein H, et al. WHO classification of tumours of haematopoietic and lymphoid tissues. Lyon: IARC Press; 2008.

5. Goto M, Onizawa K, Yanagawa T, Yamagata K, Shinozuka K, Nishikii H, et al. Human immunodeficiency virus-associated Burkitt's lymphoma in oral cavity of Japanese patient. J Oral Maxillofac Surg 2012;70:1885-90.

6. Mosalleum E, Mohamed N, Bassa FC, Dreyer WP. Oral medicine case book 69: Burkitt lymphoma of the oral cavity. South Afr Dent J 2015;70:168-70.

7. Sivolella S, Rizzo G, Valente M, Lumachi F. Sporadic Burkitt lymphoma mimicking osteomyelitis of the mandible revealing clinically unsuspected HIV infection. Anticancer Res 2015;35:4837-9.

8. Pinisetti S, Nalabolu GR, Uvr C, Tadi DP. HIV associated intra-oral Burkitt's lymphoma: a case report. J Clin Diagn Res 2013;7:30889.

9. Silva TD, Ferreira CB, Leite GB, de Menezes Pontes JR, Antunes HS. Oral manifestations of lymphoma: a systematic review. Ecancermedicalscience 2016;10:665.

10. Chen YK, Tsu HR, Lin YJ, Lin LM. Intra-oral HIV-associated Burkitt's lymphoma with mandible involvement. Oral Oncol Extra 2005;41:249-52.

11. Karlis V, Glickman RS, Isdith K, Jones JL. Right facial edema associated with localized gingival swelling. J Oral Maxillofac Surg 1998;56:760-4.

12. Jordan RC, Chong L, Dipierdomenico S, Satira F, Main JH. Oral lymphoma in human immunodeficiency virus infection: a report of six cases and review of the literature. Otolaryngol Head Neck Surg 1998;119:672-7.

13. Langford A, Dienemann D, Schürman D, Pohle HD, Pauli G, Stein $\mathrm{H}$, et al. Oral manifestations of AIDS-associated non-Hodgkin's lymphomas. Int J Oral Maxillofac Surg 1991;20:136-41.

14. Corti M, Villafañe MF, Solari R, De Carolis L, Cangelosi D, Santoro J, et al. Non-Hodgkin lymphomas of the oral cavity in AIDS patients in a reference hospital of infectious diseases in Argentina: report of eleven cases and review of the literature. J Gastrointest Cancer 2011;42:143-8.

15. Nittayananta W, Apinawatavorngul S, Chungpanich S, Pongpanich S, Kietthubthew S. Burkitt-like lymphoma presenting as a periodontal disease in AIDS patients: a report of two cases. Oral Dis 1998;4:281-4

16. Venkatesh E, Bagewadi A, Keluskar V, Shetti A. Oral non-Hodgkin's lymphoma as an initial diagnosis in a HIV positive patient. J Indian Acad Oral Med Radiol 2008;20:162-5.

17. Komatsu N, Kawase-Koga Y, Mori Y, Kamikubo Y, Kurokawa M, Takato T. HIV-associated Burkitt lymphoma in a Japanese patient with early submandibular swelling. BMC Res Notes 2013;6:557.

18. Butt FM, Chindia ML, Rana F, Machigo FG. Pattern of head and neck malignant neoplasms in HIV-infected patients in Kenya. Int J Oral Maxillofac Surg 2008;37:907-11.

19. Bellan C, Stefano L, Giulia de F, Rogena EA, Lorenzo L. Burkitt lymphoma versus diffuse large B-cell lymphoma: a practical approach. Hematol Oncol 2010;28:53-6.

20. Rosenwald A, Ott G. Burkitt lymphoma versus diffuse large B-cell lymphoma. Ann Oncol 2008;19 Suppl 4:iv67-9.

How to cite this article: Kamat M, Datar U, Kanitkar S, Byakodi S. Intraoral HIV-associated Burkitt's lymphoma: a rare case report with special emphasis on differential diagnosis. J Korean Assoc Oral Maxillofac Surg 2019;45:225-229. https://doi.org/10.5125/ jkaoms.2019.45.4.225 